\title{
ANALISIS SISTEM ANTRIAN DENGAN SIMULASI DI PUSKESMAS CEBONGAN KOTA SALATIGA
}

\author{
Puput Retno Muninggar ${ }^{1}$, Lilik Linawati ${ }^{2}$, Hanna Arini Parhusip ${ }^{3}$ \\ Universitas Kristen Satya Wacana, Jalan Diponegoro 52-60, Salatiga 50711, Indonesia \\ ${ }^{1}$ puputrm18@gmail.com
}

\begin{abstract}
Abstrak
Tujuan dari penelitian ini adalah untuk mendapatkan model sistem antrian, mengetahui karakteristik sistem antrian, dan mendapatkan hasil analisis simulasi pada sistem antrian di Puskesmas Cebongan Kota Salatiga. Pengumpulan data dilakukan dengan metode observasi langsung pada bagian Pendaftaran, bagian Cek Tekanan Darah dan bagian Periksa di Poliklinik Umum, dan bagian Pengambilan Obat. Hasil penelitian diperoleh masing-masing model antrian di bagian Pendaftaran, bagian Cek Tekanan Darah, dan bagian Pengambilan Obat adalah (G/G/1) : (FIFO/ $/ \infty / \infty)$, dimana waktu antar kedatangan dan waktu pelayanan berdistribusi general, jumlah server 1, disiplin antrian FIFO, kapasitas sistem dan kapasitas kedatangan yang tidak terbatas. Model antrian di bagian Periksa yaitu (G/G/2) : (FIFO/ / / $)$, yaitu waktu antar kedatangan dan waktu pelayanan berdistribusi general, jumlah server 2, disiplin antrian FIFO, kapasitas sistem dan kapasitas kedatangan yang tidak terbatas. Kesesuaian hasil simulasi setiap pelayanan sudah mendekati kondisi nyatanya, namun pada bagian Cek Tekanan Darah dan Pengambilan Obat terdapat beberapa karakteristik yang belum sesuai dengan kondisi nyata. Hasil simulasi rata-rata jumlah pasien dalam antrian dan rata-rata waktu pasien dalam antrian pada bagian Cek Tekanan Darah dan bagian Pengambilan Obat lebih besar dari kondisi nyata.
\end{abstract}

Kata Kunci: Model Antrian, Sistem Antrian, Simulasi

\begin{abstract}
The purpose of this study are to obtain a queuing system model, find out the characteristics of the queuing system, and obtain the results of simulation analysis on the queuing system in Cebongan Health Center, Salatiga City. Data collection is done by direct observation method in the Registration section, the Blood Pressure Check section and the Check section in the General Polyclinic, and the Drug Collection section. The results of the study were obtained by each queue model in the Registration section, the Blood Pressure Check section, and the Drug Extraction section is $(G / G / 1)$ : (FIFO/o/oo), where the time of arrival and service time are generally distributed, the number of servers 1, FIFO queue discipline, unlimited system capacity and arrival capacity. The queue model in the Check section is $(G / G / 2)$ : (FIFO/oo/o), which is the time between arrival and general distribution service time, number of servers 2, FIFO queue discipline, unlimited system capacity and arrival capacity. The suitability of the simulation results for each service is close to the actual conditions, but in the Checking Blood Pressure and Drug Taking section there are several characteristics that are not in accordance with the real conditions. The simulation results of the average number of patients in the queue and the average time of patients in the queue at the Blood Pressure Check and Drug Extraction section are greater than the real conditions.
\end{abstract}

Keywords: Queue Model, Queueing System, Simulation

\section{Pendahuluan}

Untuk memperbaiki suatu masalah antrian pelayanan dapat menggunakan suatu metode analisa dengan teori antrian. Dengan analisa teori antrian, kita dapat mengetahui apakah sistem 
pelayanan yang ada sudah mencapai suatu keadaan yang optimal atau belum. Teori antrian sebenarnya tidak bisa langsung memecahkan masalah antrian. Kelebihan dari teori antrian ini adalah memberikan informasi yang diperlukan dalam membuat keputusan dengan cara memperkirakan beberapa karakteristik dari antrian, misalnya waktu rata-rata yang diperlukan dalam antrian (Tarliah dan Dimyati, 1999:349 dalam Aminulloh, 2016).

Di Puskesmas Cebongan Kota Salatiga, masyarakat yang ingin berobat tampak ramai mengantri. Pasien yang datang harus melewati beberapa tahapan pelayanan. Pelayanan terdiri dari beberapa bagian yaitu bagian Pendaftaran, bagian Cek Tekanan Darah dan bagian Periksa di Poliklinik Umum, dan bagian Pengambilan Obat.

Tujuan penelitian ini yaitu untuk mendapatkan model sistem antrian, mengetahui karakteristik sistem antrian, dan mendapatkan hasil analisis simulasi program dari sistem antrian di Puskesmas Cebongan Kota Salatiga.

\section{Metode Penelitian}

Pengumpulan data dilakukan dengan metode observasi langsung pada subsistem antrian Pendaftaran, Cek Tekanan dan Periksa di poliklinik umum, serta Pengambilan Obat di Puskesmas Cebongan Kota Salatiga. Waktu penelitian dilakukan mulai dari tanggal 13 Agustus 2018 sampai tanggal 15 September 2018 pada pukul 07.00-selesai selama hari kerja. Setiap harinya di bagian Pendaftaran selalu ada penumpukan antrian yang disebabkan karena pasien datang lebih awal sebelum puskesmas buka.

Penerapan Sistem Antrian di Puskesmas Cebongan Kota Salatiga:

1. Organisasi data

Rekapitulasi data hasil pengamatan, yaitu waktu kedatangan pasien dan waktu pelayanan yang telah diolah dan diperoleh tingkat kedatangan $(\lambda)$ dan tingkat pelayanan $(\boldsymbol{\mu})$ beserta jumlah server (c) yang tersedia pada masing-masing bagian pelayanan disajikan pada Tabel 1.

Tabel 1 Tingkat Kedatangan dan Tingkat Pelayanan Setiap Bagian Pelayanan

\begin{tabular}{ccccc}
\hline & Pendaftaran & $\begin{array}{c}\text { Cek Tekanan } \\
\text { Darah }\end{array}$ & Periksa & $\begin{array}{c}\text { Pengambilan } \\
\text { Obat }\end{array}$ \\
\hline $\mathrm{c}$ & 1 & 1 & 2 & 1 \\
$\lambda$ (orang/detik) & 0.0058 & 0.0062 & 0.0059 & 0.0070 \\
$\boldsymbol{\mu}$ (orang/detik) & 0.0146 & 0.0166 & 0.0038 & 0.0306 \\
\hline
\end{tabular}

2. Menentukan distribusi probabilitas data

Data yang digunakan adalah data waktu antar kedatangan dan waktu pelayanan. Dalam menentukan distribusi probabilitas data digunakan uji Kolmogorov-Smirnov dengan 
bantuan software EasyFit 5.6 Profesional. Pada software ini, data diuji dengan menggunakan teknik goodness of fit metode Kolmogorov-Smirnov. Pengujian waktu antar kedatangan dalam sistem antrian yang diteliti menghasilkan parameter, dengan nilai parameter ditunjukkan pada Tabel 2.

Tabel 2 Distribusi Waktu Antar Kedatangan Setiap Bagian Pelayanan

\begin{tabular}{lcc}
\hline \multirow{2}{*}{ Bagian Pelayaan } & \multicolumn{2}{c}{ Waktu Antar Kedatangan } \\
\cline { 2 - 3 } Pendaftaran & Distribusi & Parameter \\
& Gamma & $\gamma=0$ \\
& & $\alpha=0.82698$ \\
Cek Tekanan Darah & Gen. Pareto & Mean $=162.11$ \\
& & $\mathrm{Sd}=196.65$ \\
Periksa & Burr & Mean $=168.23$ \\
Pengambilan Obat & Gen. Pareto & $\mathrm{Sd}=181.66$ \\
& & $\mathrm{Sd}=144.68$ \\
\hline
\end{tabular}

Sedangkan hasil uji distribusi waktu pelayanan sistem antrian di Puskesmas Cebongan Kota Salatiga dengan parameter yang digunakan disajikan dalam Tabel 3.

Tabel 3 Distribusi Waktu Pelayanan Setiap Bagian Pelayanan

\begin{tabular}{lcc}
\hline \multirow{2}{*}{ Bagian Pelayaan } & \multicolumn{2}{c}{ Waktu Pelayanan } \\
\cline { 2 - 3 } Pendaftaran & Distribusi & Parameter \\
\multirow{2}{*}{ Cek Tekanan Darah } & Lognormal & $\sigma=0.9693$ \\
& & $\mu=3.7555$ \\
Periksa & Log-Logistic & Mean $=60.321$ \\
& Gen. Pareto & $\mathrm{Sd}=10.658$ \\
Pengambilan Obat & & $\mathrm{Sd}=131.31$ \\
& Burr & $\mathrm{Mean}=32.678$ \\
& & $\mathrm{Sd}=20.051$ \\
\hline
\end{tabular}

3. Menentukan model sistem antrian berdasarkan distribusi probabilitas

Berdasarkan distribusi probabilitas pada Tabel 2 dan Tabel 3 diperoleh model antrian untuk setiap bagian pelayanan yang disajikan dalam Tabel 4.

Tabel 4 Model Antrian Setiap Bagian Pelayanan

\begin{tabular}{lc}
\hline \multicolumn{1}{c}{ Bagian Pelayaan } & Model \\
\hline Pendaftaran & $(\mathrm{G} / \mathrm{G} / 1):(\mathrm{FIFO} / \infty / \infty)$ \\
Cek Tekanan Darah & $(\mathrm{G} / \mathrm{G} / 1):(\mathrm{FIFO} / \infty / \infty)$ \\
Periksa & $(\mathrm{G} / \mathrm{G} / \mathrm{c}):(\mathrm{FIFO} / \infty / \infty)$ \\
Pengambilan Obat & $(\mathrm{G} / \mathrm{G} / 1):(\mathrm{FIFO} / \infty / \infty)$ \\
\hline
\end{tabular}

Pada Tabel 4 dapat dijelaskan berdasarkan notasi Kendall bahwa distribusi probabilitas waktu antar kedatangan dan waktu pelayanan yang diperoleh pada Tabel 2 dan Tabel 3 dapat diasumsikan berdistribusi general (umum), karena distribusi yang diperoleh 
bukanlah distribusi Eksponensial, Erlang, ataupun dengan waktu pelayanan konstan. Jumlah server setiap bagian pelayanan yaitu masing-masing sebanyak 1 server pada bagian Pendaftaran, Cek Tekanan Darah, serta Pengambilan Obat, dan sebanyak c server atau lebih dari satu server pada bagian Periksa, dimana telah diketahui berdasarkan tabel 1 bahwa jumlah server (c) pada bagian Periksa terdapat 2 server. Disiplin antrian adalah FIFO atau yang pertama dilayani adalah yang datang lebih awal. Kapasitas sistem dan sumber kedatangan yang tidak terbatas.

4. Menghitung ukuran steady state dan karakteristik sistem antrian.

5. Melakukan simulasi menggunakan software Queueing Analysis pada WINQSB.

\section{Hasil dan Pembahasan}

Hasil perhitungan analitik yang diperoleh sesuai dengan formula model antrian setiap bagian pelayanan disajikan dalam Tabel 5 .

Tabel 5. Hasil Perhitungan Analitik Model Sistem Antrian Setiap Bagian Pelayanan

\begin{tabular}{crrrr}
\hline & Pendaftaran & $\begin{array}{c}\text { Cek Tekanan } \\
\text { Darah }\end{array}$ & \multicolumn{1}{c}{ Periksa } & $\begin{array}{c}\text { Pengambilan } \\
\text { Obat }\end{array}$ \\
\hline Model & $(\mathrm{G} / \mathrm{G} / 1):$ & $(\mathrm{G} / \mathrm{G} / 1):$ & $(\mathrm{G} / \mathrm{G} / 2):$ & $(\mathrm{G} / \mathrm{G} / 1):$ \\
Antrian & $(\mathrm{FIFO} / \infty / \infty)$ & $(\mathrm{FIFO} / \infty / \infty)$ & $(\mathrm{FIFO} / \infty / \infty)$ & $(\mathrm{FIFO} / \infty / \infty)$ \\
$\boldsymbol{\rho}$ & 0.3973 & 0.3735 & 0.7763 & 0.2288 \\
$\boldsymbol{L}$ (orang) & 0.6591 & 0.5962 & 3.1984 & 0.2966 \\
$\boldsymbol{L} \boldsymbol{q}$ (orang) & 0.2618 & 0.2227 & 1.6458 & 0.0679 \\
$\boldsymbol{W}$ (detik) & 113.1432 & 96.1538 & 542.1092 & 42.3729 \\
$\boldsymbol{W} \boldsymbol{q}$ (detik) & 45.1432 & 35.9129 & 278.9513 & 9.6931 \\
$\boldsymbol{P o}$ & 0.6027 & 0.6265 & 0.1259 & 0.7712 \\
\hline
\end{tabular}

Pada Tabel 5 dapat diketahui bahwa nilai $\rho$ kurang dari 1 atau dapat dikatakan bahwa sistem antrian setiap bagian pelayanan telah memenuhi kondisi steady state atau stabil, yaitu tingkat kedatangan pasien tidak lebih cepat dari tingkat pelayanannya.

Rata-rata jumlah pasien yang menunggu dalam sistem $(L)$ yang terbesar terdapat pada bagian Periksa yaitu sebanyak 3.1984 atau sekitar 3 orang, dan yang terkecil terdapat pada bagian Pengambilan Obat yaitu sebanyak 0.2966 orang. Karena bilangan banyaknya orang harus tidak negatif, maka pada bagian Pengambilan Obat dapat dikatakan bahwa pasien yang menunggu dalam sistem hampir tidak ada.

Rata-rata jumlah pasien yang menunggu dalam antrian $(L q)$ terbesar ada pada bagian Periksa yaitu sebanyak 1.6458 atau sekitar 2 orang, dan terkecil ada pada bagian Pengambilan Obat yaitu sebanyak 0.0679 orang. Karena bilangan banyaknya orang haruslah bilangan bulat positif, maka pada bagian Pengambilan Obat dapat dikatakan bahwa pasien yang menunggu dalam antrian hampir tidak ada. 
Rata-rata waktu pasien dalam sistem $(W)$ yang terbesar terdapat pada bagian Periksa yaitu sekitar 542 detik atau 9 menit 2 detik untuk setiap pasien, dan yang terkecil terdapat pada bagian Pengambilan Obat yaitu sekitar 42 detik untuk setiap pasien. Total rata-rata waktu pasien dalam sistem adalah sekitar 369 detik atau 6 menit 9 detik

Rata-rata waktu pasien dalam antrian ( $W q$ )yang terbesar terdapat pada bagian Periksa yaitu sekitar 279 detik atau 4 menit 39 detik untuk setiap pasien, dan yang terkecil terdapat pada bagian Pengambilan Obat yaitu sekitar 10 detik untuk setiap pasien. Total rata-rata waktu pasien dalam sistem adalah sekitar 794 detik atau 13 menit 14 detik. Total rata-rata waktu pasien dalam sistem pada kondisi nyata sekitar 11 menit 19 detik. Karena perbedaanya tidak terlalu besar, maka dapat dikatakan rata-rata waktu pasien dalam sistem hasil analitik sesuai dengan kondisi nyata.

Probabilitas terbesar dimana dalam sistem tidak ada pelanggan terdapat pada bagian Pengambilan Obat yaitu sebesar 0.7712 atau $77.12 \%$ dari waktu kerjanya. Sedangkan probabilitas yang paling kecil ada pada bagian Periksa yaitu 0.1259 atau $12.59 \%$ dari waktu kerjanya.

Software WINQSB dapat digunakan untuk perhitungan karakteristik sistem antrian, selain itu software ini juga dapat membantu dalam mensimulasikan sistem antrian. Simulasi dilakukan dengan waktu pelayanan selama 18000 detik atau selama 3 jam. Digunakan asumsi presentase selisih terhadap hasil simulasi kurang dari 50\% untuk menyatakan hasil simulasi sesuai dengan kondisi nyatanya. Berdasarkan hasil perhitungan analitik serta hasil analisis simulasi diperoleh perbandingan ukuran karakteristik disajikan pada Tabel 6.

Tabel 6a Perbandingan Hasil Analitik dan Simulasi Pada Bagian Pendaftaran

\begin{tabular}{crrrr}
\hline & Analitik & Simulasi & Selisih & Presentase (\%) \\
\hline $\boldsymbol{\rho}$ & 0.3973 & 0.3281 & 0.0692 & 21.09 \\
$L$ (orang) & 0.6591 & 0.5404 & 0.1187 & 21.97 \\
$L q$ (orang) & 0.2618 & 0.2123 & 0.0495 & 23.32 \\
$W$ (detik) & 113.1432 & 112.4594 & 0.6838 & 0.61 \\
$W q$ (detik) & 45.1432 & 43.7770 & 1.3662 & 3.12 \\
$P o$ & 0.6027 & 0.6719 & 0.0692 & 10.30 \\
\hline
\end{tabular}

Dari Tabel 6a dapat diketahui bahwa hasil simulasi subsistem antrian pada bagian Pendaftaran dapat dikatakan cukup sesuai dengan kondisi nyatanya.

Tabel 6b Perbandingan Hasil Analitik dan Simulasi Pada Bagian Cek Tekanan Darah

\begin{tabular}{crrrr}
\hline & Analitik & Simulasi & Selisih & Presentase $(\%)$ \\
\hline $\boldsymbol{\rho}$ & 0.3735 & 0.3645 & 0.0090 & 2.47 \\
$L$ (orang) & 0.5962 & 0.9587 & 0.3625 & 37.81 \\
$L q$ (orang) & 0.2227 & 0.5941 & 0.3714 & 62.51 \\
$W$ (detik) & 96.1538 & 155.2708 & 59.117 & 38.07 \\
$W q$ (detik) & 35.9129 & 94.88279 & 58.9699 & 62.15
\end{tabular}




\begin{tabular}{lllll} 
Po & 0.6265 & 0.6361 & 0.0096 & 1.51 \\
\hline
\end{tabular}

Dari Tabel 6b dapat diketahui bahwa hasil simulasi subsistem antrian pada bagian Tek Tekanan Darah dapat dikatakan cukup sesuai dengan kondisi nyatanya untuk ukuran steady state $(\rho)$, rata-rata pasien yang menunggu dalam sistem $(L)$, rata-rata waktu pasien dalam sistem $(W)$, dan probabilitas dalam sistem tidak ada pasien $(\mathrm{Po})$. Sedangkan untuk rata-rata pasien yang menunggu dalam antrian $(L q)$ dan rata-rata waktu pasien dalam antrian $(W q)$ kurang sesuai dengan kondisi nyatanya.

Tabel 6c Perbandingan Hasil Analitik dan Simulasi Pada Bagian Periksa

\begin{tabular}{crrrr}
\hline & Analitik & Simulasi & Selisih & Presentase $(\%)$ \\
\hline$\rho$ & 0.7763 & 0.8077 & 0.0314 & 3.89 \\
$L$ (orang) & 3.1984 & 3.3716 & 0.1732 & 5.14 \\
$L q$ (orang) & 1.6458 & 1.8428 & 0.1970 & 10.69 \\
$W$ (detik) & 542.1092 & 548.6451 & 6.5359 & 1.19 \\
$W q$ (detik) & 278.9513 & 288.8283 & 9.8770 & 3.42 \\
$P o$ & 0.1259 & 0.1135 & 0.0124 & 10.93 \\
\hline
\end{tabular}

Dari Tabel 6c dapat diketahui bahwa hasil simulasi subsistem antrian pada bagian Periksa dapat dikatakan cukup sesuai dengan kondisi nyatanya.

Tabel 6d Perbandingan Hasil Analitik dan Simulasi Pada Bagian Pengambilan Obat

\begin{tabular}{crrrr}
\hline & Analitik & Simulasi & Selisih & Presentase $(\%)$ \\
\hline $\boldsymbol{\rho}$ & 0.2288 & 0.2274 & 0.0014 & 0.62 \\
$L$ (orang) & 0.2966 & 0.4755 & 0.1789 & 37.62 \\
$L q$ (orang) & 0.0679 & 0.2497 & 0.1818 & 72.81 \\
$W$ (detik) & 42.3729 & 67.8942 & 25.5213 & 37.59 \\
$W q$ (detik) & 9.6931 & 35.2899 & 25.5968 & 72.53 \\
$P o$ & 0.7712 & 0.7726 & 0.0014 & 0.18 \\
\hline
\end{tabular}

Dari Tabel 6d dapat diketahui bahwa hasil simulasi subsistem antrian pada bagian Pengambilan Obat dapat dikatakan cukup sesuai dengan kondisi nyatanya untuk ukuran steady state $(\rho)$, rata-rata pasien yang menunggu dalam sistem $(L)$, rata-rata waktu pasien dalam sistem $(W)$, dan probabilitas dalam sistem tidak ada pasien $(\mathrm{Po})$. Sedangkan untuk rata-rata pasien yang menunggu dalam antrian $(L q)$ dan rata-rata waktu pasien dalam antrian $(W q)$ kurang sesuai dengan kondisi nyatanya.

Dari pembahasan pada Tabel $6 \mathrm{~b}$ dan Tabel $6 \mathrm{~d}$ rata-rata pasien yang menunggu dalam antrian $(L q)$ dan rata-rata waktu pasien dalam antrian $(W q)$ diperoleh hasil simulasi kurang sesuai dengan kondisi nyatanya. Maka perlu dilakukan perbaikan model dengan memperhatikan keakurasian dalam pengambilan data. 


\section{Simpulan dan Saran}

Berdasarkan hasil penelitian yang telah dilakukan dapat disimpulkan bahwa model antrian masing-masing pada bagian Pendaftaran, Cek Tekanan Darah, dan Pengambilan Obat yaitu

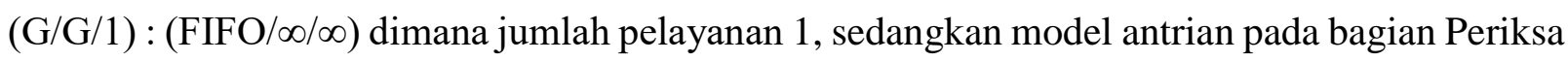

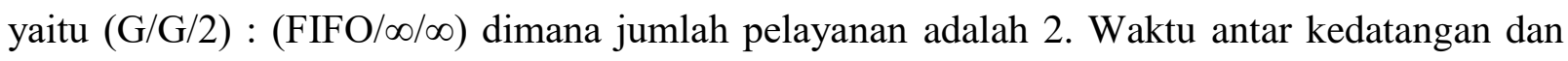
waktu pelayanan berdistribusi general. Disiplin antrian FIFO, kapasitas sistem dan sumber kedatangan tak terbatas.

Ukuran karakteristik yang terbesar terdapat pada bagian Periksa yaitu rata-rata jumlah pasien yang menunggu dalam sistem sekitar 3 orang, rata-rata jumlah pasien yang menunggu dalam antrian sekitar 2 orang, rata-rata waktu pasien dalam sistem sekitar 9 menit 2 detik, ratarata pasien dalam antrian sekitar 4 menit 39 detik, dan dengan probabilitas dalam sistem tidak ada pasien sebesar $12.59 \%$. Sedangkan ukuran karakteristik yang terkecil terdapat pada bagian Pengambilan Obat yaitu hampir tidak ada pasien yang menunggu dalam sistem maupun dalam antrian, rata-rata waktu pasien dalam sistem sekitar 42 detik, rata-rata waktu pasien dalam antrian sekitar 10 detik, dan dengan probabilitas dalam sistem tidak ada pasien sebesar $77.12 \%$.

Kesesuaian hasil simulasi setiap bagian pelayanan sudah mendekati kondisi nyatanya, namun pada bagian Cek Tekanan Darah dan Pengambilan Obat, hasil simulasi rata-rata pasien yang menunggu dalam antrian dan rata-rata waktu pasien dalam antrian lebih besar dari nyata.

Adapun saran untuk penelitian mendatang yaitu perlu dilakukan perbaikan model dengan memperhatikan keakurasian dalam pengambilan data, penelitian dengan memperhatikan kedatangan pasien yang datang pertama dan berdasarkan hasil yang diperoleh dalam penelitian ini, kinerja pelayanan di Puskesmas Cebongan Kota Salatiga sudah baik, maka pasien tidak perlu datang terlalu awal sebelum puskesmas buka.

\section{Referensi}

Aminulloh, A.F. 2016. Analisis Model Antrian Multi Phase (Studi Kasus di SAMSAT Kota Pasuruan). Skripsi Jurusan Matematika, Fakultas Sains dan Teknologi, Universitas Islam Negeri Maulana Malik Ibrahim Malang.

Artiguna, Purina P., Sugito, dan Hoyyi, A. 2014. Analisis Sistem Antrian Pada Layanan Pengurusan Paspor Di Kantor Imigrasi Kelas I Semarang. Jurnal Gaussian, Vol. 3, No. 4, Hal. 801-810, ISSN: 2339-2541.

Farkhan, Feri.2013. Aplikasi Teori Antrian dan Simulasi Pada Pelayanan Teller Bank. Skripsi Jurusan Matematika, Fakultas Matematika dan Ilmu Pengetahuan Alam, Universitas Negeri Semarang.

Nindyaiswari, N., Sugito, dan Wilandari, Y. 2015. Identifikasi Antrian Bus Rapid Transit (BRT) Pada Halte Operasional BRT Semarang. Jurnal Gaussian, Vol. 4, No. 3, Hal. 593-601, ISSN: 2339-2541. 
Putranto, M.A. 2014. Analisis Masalah Sistem Antrian Model Multi Phase Pada kantor SAMSAT Yogyakarta. Skripsi Jurusan Pendidikan Matematika, Fakultas Matematika dan Ilmu Pengetahuan Alam, Universitas Negeri Yogyakarta.

Shortle, J.F., Thompson, J.M., dkk. 2018. Fundamentals of Queueing Theory. 5th Edition. John Wiley and Sons, Inc.

Taha, HA. 2007. Operation Research Introduction. 8th Edition. Pearson Prentice Hall.

Taylor III BW. 2005. Introduction to Management Science. 8th Edition. Prentice Hall Pearson Education, Inc.

Winston, W.L. 2004. Operations Research Aplications and Algorithms. 4th Edition. Thomson Learning.

Yowoso, G.C. 2015. Analisis Sistem Antrian Service Mobil di PT. Tunas Mobilindo Perkasa dengan Menggunakan Simulasi Arena. Skripsi Jurusan Teknik Industri, Fakultas Teknik, Universitas Darma Persada Jakarta. 